\title{
Availability of Dental Prosthesis Procedures in Brazilian Primary Health Care
}

\author{
Maria Aparecida Gonçalves Melo Cunha, ${ }^{1}$ Antônio Thomaz Gonzaga Matta-Machado, ${ }^{2}$ \\ Simone Dutra Lucas, ${ }^{1}$ and Mauro Henrique Nogueira Guimarães Abreu (D) ${ }^{1}$ \\ ${ }^{1}$ Department of Community and Preventive Dentistry, Universidade Federal de Minas Gerais, Belo Horizonte, MG, Brazil \\ ${ }^{2}$ Department of Social and Preventive Medicine, Universidade Federal de Minas Gerais, Belo Horizonte, MG, Brazil
}

Correspondence should be addressed to Mauro Henrique Nogueira Guimarães Abreu; maurohenriqueabreu@gmail.com

Received 12 November 2017; Accepted 16 January 2018; Published 11 February 2018

Academic Editor: Konstantinos Michalakis

Copyright (C) 2018 Maria Aparecida Gonçalves Melo Cunha et al. This is an open access article distributed under the Creative Commons Attribution License, which permits unrestricted use, distribution, and reproduction in any medium, provided the original work is properly cited.

\begin{abstract}
Objectives. To describe dental prosthesis provision in the Brazilian public health service and report the performance of dental prosthesis procedures according to the Brazilian macroregions. Methods. A structured interview was conducted with senior-level health professionals from each of the 18,114 oral health teams (OHT). The dependent variables were performance of removable prostheses and prosthesis procedures, including provision of fixed prostheses by OHT. Descriptive statistics were produced together with performing a cluster analysis using SPSS version 19.0. Results. The manufacture of any type of prosthesis was done by a minority of OHT (43\%). The most commonly provided types of dental prosthesis were removable full and partial dentures. Cluster 1 (teams that performed prosthesis procedures the most) was composed of a smaller number of teams $(n=5,531$ ), and Cluster 2 (composed of teams that do not perform prosthetics or that perform them in small amounts) consisted of 12,583 teams. The geographic distribution of clusters reveals that the largest proportion of Cluster 1 teams is located in the Northeast (33.9\%) and Southeast (33.6\%). Conclusions. A minority of OHT produce dental prostheses. There is an unequal geographical distribution of clusters.
\end{abstract}

\section{Introduction}

The prevalence of tooth loss and the need for prosthetic treatment are high both in Brazil and worldwide $[1,2]$ and affect the well-being of individuals and the population [3]. To improve oral health-related quality of life, rehabilitation with removable or fixed prostheses is indicated to reestablish masticatory and aesthetic functions and to minimize the consequences of tooth loss and edentulism [4]. Nevertheless, access to prostheses is hampered by the limited economic condition of the population [5] and low supply of this procedure in the public health system [6]. In view of this reality, the Brazilian National Oral Health Policy included the implementation of total and partial, removable, and fixed prosthesis procedures in primary health care (PHC) services [7].

In 2011, the Ministry of Health (MS) developed a policy to evaluate the quality of services provided by PHC in Brazil, namely, the National Program for Improving Access and Quality of Basic Care (PMAQ-AB). According to the results of evaluation of the health teams, they can receive a financial incentive for the continuity of systematic progress. Previous studies based on data from the PMAQ-AB have already evaluated the performance of dental procedures $[8,9]$ and oral health preventive procedures [10], as well as the interrelation between PHC and specialized care [11]. However, despite financial incentives provided by the Brazilian MS to expand and qualify PHC, no detailed evaluation of the performance of prosthetic procedures has been carried out as yet. A better understanding of dental prosthesis provision by $\mathrm{PHC}$ services in Brazil can provide data to better organize work processes of oral health professionals, favoring improved response to the demands of the population.

In this context, this study aimed to describe dental prosthesis production in the public health service provided by the oral health teams (OHT) of the family health strategy (FHS) 
in Brazil. Secondarily, the performance of dental prostheses according to the Brazilian macroregions was described.

\section{Methods}

This descriptive study used data from the second PMAQ-AB cycle of PHC teams, conducted by the Brazilian MS between 2013 and 2014. This program aimed to improve access and quality of PHC through technical and economic support. Each FHS team underwent a certification process based on the results of an external evaluation and analysis of health indicators. The PMAQ-AB was based on the Donabedian model that establishes a fundamental conceptual framework for the understanding of health quality assessment, based on the concepts of structure, process, and outcome $[9,12]$.

The interviewed population consisted of Brazilian dentists who worked in the OHT and participated in the second cycle of PMAQ-AB. In January 2013, 23,251 OHT were implanted in Brazil. In contrast to what happened in the first cycle of PMAQ-AB, where only $50 \%$ of all teams could participate in the program, municipal managers were able to indicate the number of OHT they assessed to be able to participate in the second cycle. A total of 18,114 (77.9\%) OHT, each one with one dentist, underwent an external evaluation process and were part of that study. Thus, a questionnaire was developed and included, among other items, questions about the dental procedures performed. For this study, the main question was "Which type (s) of prostheses is (are) offered in primary health care: you may select more than one response option: total removable prosthesis, partial removable prosthesis, fixed dental prosthesis, temporary removable dental prosthesis." The questionnaire was structured using mainly dichotomous questions. For this evaluation, in addition to interviews with OHT dentists about their work processes, PHC documents were also verified. Both the elaboration of the questionnaire used for the interview and data collection with professionals were carried out with the participation of 46 Brazilian education and research institutions. The 989 interviewers were all senior health professionals and were trained to conduct this survey nationwide. This 40-hour training included PHC content, survey methods, and PMAQ questionnaires. All interviewers were submitted to a formal evaluation to access their abilities. One supervisor was assigned to each 3 interviewers. The Brazilian Ministry of Health developed an app for mobile devices, which had the questions in electronic format that allowed data collection. Data was sent online via Internet directly to the database of the Ministry of Health that was responsible for the consistency analysis and certification of the health teams. So, the dataset was organized automatically, with no need for data typists. The dentists interviewed were volunteers and could refuse to attend.

Descriptive statistics and a cluster analysis (clustering) were performed using SPSS for Windows version 19.0, for the following variables: "performs total prosthesis," "performs partial removable prosthesis," "performs temporary prosthesis," and "performs fixed prosthesis." The hierarchical agglomeration technique with complete chaining based on the most distant neighbor was used. This explanatory data analysis technique for organizing observed data (in our case, from OHT) into groups (clusters) builds on combinations of independent variables (in our case, reports of dental prosthesis procedures) and enhances the similarity of cases within each cluster while maximizing the dissimilarity between groups. In our study, three sets of clusters (with two to four clusters) were formed from the 18,114 OHT, and the choice of two clusters was based on the improved understanding of the phenomenon (the characteristics of dental prosthesis procedures reports) [13]. Clusters were also identified according to their geographic location in the Brazilian macroregions. A Choropleth map was drawn to show the proportions of Cluster 1 in each Brazilian geographic macroregion.

\section{Results}

Of the 18,114 OHT studied, some type of prosthesis procedure was performed by $43 \%$ of the teams. The most commonly performed types of dental prosthesis procedure are described in Table 1.

Cluster 1 consists of a smaller number of teams $(n=5,531)$ that perform prosthesis procedures more frequently. Cluster 2 is composed of teams that do not make any kinds of prosthesis procedure or make them in small numbers. A higher number of OHT are part of Cluster $2(n=12,583)$. The frequency of prosthesis procedure performance in $\mathrm{PHC}$ is described in Table 2.

The geographic distribution of clusters reveals that the largest proportion of Cluster 1 teams is located in the Northeast and Southeast regions (33.9\% and 33.6\%, resp.), followed by the South (31.1\%) and Midwest (20.3\%); the lowest proportion of teams performing these services was found in the Northern region (9.3\%) (Table 3 and Figure 1).

\section{Discussion}

This study described the dental prosthesis procedures performed by PHC OHT in Brazil. The results showed that less than half (43\%) of the OHT performed some type of prosthesis procedure, unveiling the need to scale up the accomplishment of these procedures. These OHT are unequally distributed throughout the Brazilian geographical regions.

The preparation of prosthesis procedures requires infrastructure and skilled labor force for this service. The availability and distribution of regional prosthodontic laboratories in the country have not followed the epidemiological need, and the increased number of these regional facilities and growth of prosthesis production have been discrete in recent years [14]. Another factor that can directly influence the performance of prosthesis procedures is professional training. A recent study [15] showed that the technical capacity of dentists (CD) was a problem reported by many municipalities as a reason for noncompliance with prostheses. This corroborates with the work of Donabedian [16], who said that physical facilities and professional technical knowledge are important realms for assessing the quality of a service.

The profile of the professionals that make up the OHT can also directly influence the performance of such procedures. Oftentimes, the dentist has a traditional practice and is 
TABLE 1: Frequency of dental prosthesis procedures in primary health care, Brazil, 2013-2014.

Variable $(n=18,114)$

OHT performed: total removable prosthesis

OHT performed: partial removable prosthesis

OHT performed: fixed dental prosthesis

OHT performed: temporary removable dental prosthesis

TABLE 2: Frequency of dental prosthesis procedures in primary health care among two clusters, Brazil, 2013-2014.

\begin{tabular}{|c|c|c|}
\hline Variable & $\begin{array}{c}\text { Cluster } 1 \\
(n=5,531) \\
(\%)\end{array}$ & $\begin{array}{c}\text { Cluster } 2 \\
(n=12,583) \\
(\%)\end{array}$ \\
\hline OHT performed: total removable prosthesis & 99.0 & 17.7 \\
\hline OHT performed: partial removable prosthesis & 100 & 0 \\
\hline OHT performed: fixed dental prosthesis & 8.3 & 0.4 \\
\hline OHT performed: temporary removable dental prosthesis & 23.9 & 2.9 \\
\hline
\end{tabular}

TABLe 3: Proportion of the two clusters according to Brazilian geographical region in 2013-2014.

\begin{tabular}{lcc}
\hline Brazilian geographical region & Cluster $1(n=5,531)$ & Cluster 2 $(n=12,583)$ \\
& $\%$ & 90.7 \\
\hline North $(n=1,263)$ & 9.3 & 66.1 \\
Northeast $(n=7,700)$ & 33.9 & 79.7 \\
Midwest $(n=1,572)$ & 20.3 & 66.4 \\
Southeast $(n=5,027)$ & 33.6 & 68.9 \\
South $(n=2,552)$ & 31.1 & \\
\hline
\end{tabular}

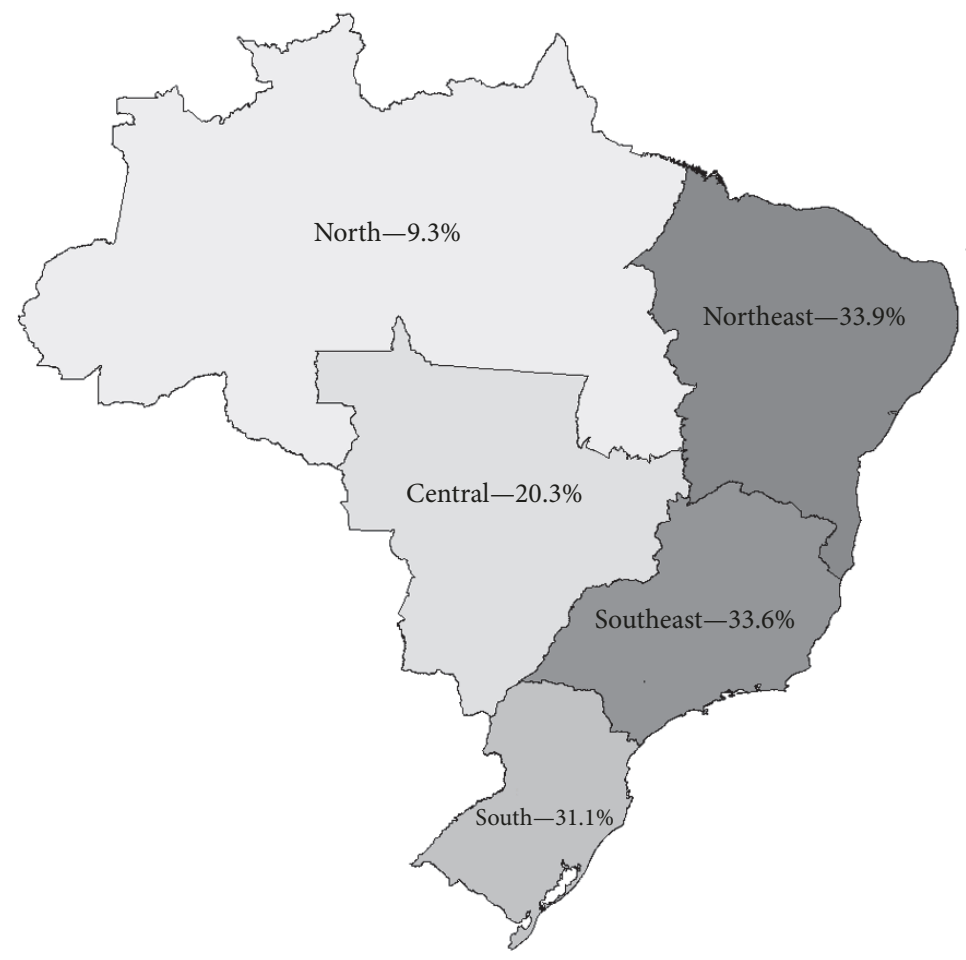

FIGURE 1: Distribution of Cluster 1 in each Brazilian geographic macroregion. 
resistant to the introduction of new technologies [17], such as the provision of prostheses in PHC.

Of the prosthesis procedures performed, those involving the (total and partial) removable type were reported most commonly by OHT. This finding may be associated with the needs of the population. Recent epidemiological studies in Brazil showed that the populations that most needed prostheses were the elderly (92.7\%) and adults (68.8\%) [18]. When dental losses are total or involve a large number of elements, removable prostheses are the most efficient alternatives for the rehabilitation of the conditions at hand [19]. Xie et al. [20] also showed that removable prostheses remain a viable and predictable treatment choice in dental practice.

Another important factor that can define the provision of a greater number of removable prostheses is cost. In many countries, partially dentate patients receive removable prostheses as standard treatment for missing elements [21]. An alternative would be prostheses retained by implants with high efficacy but low efficiency [22]. Many patients with partial loss of dental elements choose a removable prosthesis because it is more conservative, is faster to manufacture, and has a lower cost than prostheses retained by an implant [4].

Regional differences reveal inequalities in dental prosthesis procedures performed by PHC. It is worth noting that a large number of OHT that carried out most prosthesis procedures are concentrated in the Northeast. This can be explained by the investments in oral health made by public authorities in this region. The oral health survey performed in 2003 showed that oral health conditions in this region required massive public investment [23]. This region is also the one with the highest number of regional PHC-accredited prosthodontics laboratories [14]. The Southeast has the country's largest population and also the largest public health care network [24]. The North has peculiar characteristics, such as the greatest territorial extension and a low population density. This region faces major economic and social challenges [11] and also one of highest needs for dental prostheses [11,25].

Cross-sectional descriptive studies have a low analytical power, which is a limitation of this study. In addition, in the second cycle of PMAQ-AB, municipal managers indicated the number of OHT that they deemed could participate, probably indicating teams with the best structure and organization. Despite the limitations pointed out, this study evaluates a significant number of OHT, in a country with great territorial extension, and the organization of primary care at the national level. The PMAQ is a very comprehensive evaluation of oral health that is geared to be implemented every 2 years. This allows the production of longitudinal data, which will facilitate monitoring and evaluation of oral health policies in Brazil. PHC is provided to citizens through the FHS and, increasingly, OHT add integrality of care to these teams. Describing FHS OHT prosthesis procedures through their participation in major national research is an important basis for further exploring the quality of care provided to citizens. Future studies could incorporate the provision of prostheses, the quality of prostheses, and patients' adherence to the use of prostheses. Analytical epidemiological studies are also important to achieve an understanding of the factors associated with the performance of these clinical procedures.
Such advances in oral health assessment studies especially with a focus on oral rehabilitation generate scientific knowledge on the subject and gains in the quality of oral health care for the population.

\section{Conclusion}

A minority of OHT produce dental prostheses. The geographical distribution of clusters is unequal.

\section{Ethical Approval}

The Research Ethics Committee of the Federal University of Minas Gerais approved this research under no. 02396512.8.0000.5149.

\section{Conflicts of Interest}

All the authors declare that there were no conflicts of interest associated with this publication and there has been no financial support for this work that could have influenced its outcome.

\section{Authors' Contributions}

All authors contributed equally to this work.

\section{Acknowledgments}

The authors would like to acknowledge the CNPq (National Council for Scientific and Technological Development) and the Brazilian Health Surveillance Agency (ANVISA) and FAPEMIG. They also would like to thank Dr. Daisy Xavier de Abreu and Hugo André da Rocha (Núcleo de Educação em Saúde Coletiva da Faculdade de Medicina da UFMG) for drawing the map.

\section{References}

[1] A. P. Syed, A. I. S. Fad, I.-M. M. A. A. Bandar, and I. E. Eleatic, "Dental prosthetic status and treatment needs of adult population in Jizan, Saudi Arabia: a survey report," European Journal of Dentistry, vol. 10, pp. 459-463, 2016.

[2] F. R. Rodriguez, N. Paganoni, R. Weiger, and C. Walter, "Lower education level is a risk factor for tooth loss - analysis of a Swiss population (KREBS Project)," Oral Health \& Preventive Dentistry, vol. 15, pp. 139-145, 2017.

[3] P. F. Allen and A. S. McMillan, "A review of the functional and psychosocial outcomes of edentulousness treated with complete replacement dentures," Journal of the Canadian Dental Association, vol. 69, p. 662, 2003.

[4] S. Shaghaghian, M. Taghva, J. Abduo, and R. Bagheri, "Oral health-related quality of life of removable partial denture wearers and related factors," Journal of Oral Rehabilitation, vol. 42, no. 1, pp. 40-48, 2015.

[5] A. A. A. Ferreira, G. Piuvezam, C. W. A. Werner, and M. S. C. F. Alves, "A dor e a perda dentária: representações sociais do cuidado à saúde bucal," Cien Saude Colet, vol. 11, pp. 211-217, 2006. 
[6] E. Widstrom, J. Linden, H. Tiira, T. T. Seppala, and M. Ekqvist, "Treatment provided in the Public Dental Service," Community Dental Health, vol. 32, pp. 60-64, 2009.

[7] R. D. S. Pinto, D. L. Matos, and A. I. D. L. Filho, "Characteristics associated with the use of dental services by the adult brazilian population," Ciencia \& Saúde Coletiva, vol. 17, no. 2, pp. 531-544, 2012.

[8] C. M. Reis, J. V. Mambrini, A. T. da Matta-Machado, J. H. Amaral, M. A. Werneck, and M. H. Abreu, "Primary dental care evaluation in Brazil: an item response theory approach," Journal of Public Health Dentistry, vol. 77, no. 4, pp. 317-324, 2017.

[9] C. M. Reis, A. T. Matta-Machado, J. H. Amaral, M. A. Werneck, and M. H. Abreu, "Describing the primary care actions of oral health teams in Brazil," International Journal of Environmental Research and Public Health, vol. 12, pp. 667-678, 2015.

[10] M. Neves, J. M. Do Amaral Giordani, A. A. Ferla, and F. N. Hugo, "Primary care dentistry in Brazil: From prevention to comprehensive care," The Journal of Ambulatory Care Management, vol. 40, no. 2, pp. S35-S48, 2017.

[11] R. C. Martins, C. M. R. Dos Reis, A. T. G. Da Matta Machado, J. H. L. Do Amaral, M. A. F. Werneck, and M. H. N. G. De Abreu, "Relationship between primary and secondary dental care in public health services in Brazil," PLoS ONE, vol. 11, no. 10, Article ID e0164986, 2016.

[12] A. Donabedian, "Evaluating the quality of medical care," Milbank Quarterly, vol. 83, no. 4, pp. 691-729, 2005.

[13] R. A. Johnson and D. W. Wichern, Applied multivariate statistical analysis, Prentice Hall, Upper Saddle River, NJ, USA, 2007.

[14] V. R. Aguiar and R. K. Celeste, "Necessidade e alocação de laboratórios regionais de prótese dentária no Brasil: um estudo exploratório," Ciência \& Saúde Coletiva, vol. 20, no. 10, pp. 31213128, 2015.

[15] M. R. C. Guimarães, R. S. Pinto, J. H. Amaral, and A. M. D. Vargas, "Challenges related to dental prosthesis offer in the public health system," Rev Odontol UNESP, vol. 46, pp. 39-44, 2017.

[16] A. Donabedian, "The seven pillars of quality," Archives of Pathology \& Laboratory Medicine, vol. 114, pp. 1115-1118, 1990.

[17] Y. P. De Araújo and M. Dimenstein, "Structure and organization of the work of dentists in the Family Health Program of some Municipal Districts of Rio Grande do Norte (Brazil)," Ciencia \& Saúde Coletiva, vol. 11, no. 1, pp. 219-227, 2006.

[18] M. A. Peres, P. R. Barbato, S. C. G. B. Reis, C. H. S. D. M. Freitas, and J. L. F. Antunes, "Tooth loss in Brazil: analysis of the 2010 brazilian oral health survey," Revista de Saúde Pública, vol. 47, no. 3, pp. 78-89, 2014.

[19] N. U. Zitzmann, E. Hagmann, and R. Weiger, "What is the prevalence of various types of prosthetic dental restorations in Europe?" Clinical Oral Implants Research, vol. 18, no. 3, pp. $20-$ 33, 2007.

[20] Q. Xie, T. Ding, and G. Yang, "Rehabilitation of oral function with removable dentures - still an option?" Journal of Oral Rehabilitation, vol. 42, no. 3, pp. 234-242, 2015.

[21] G. McKenna, S. Tada, N. Woods, M. Hayes, C. DaMata, and P. F. Allen, "Tooth replacement for partially dentate elders: a willingness-to-pay analysis," Journal of Dentistry, vol. 53, pp. 5156, 2016.

[22] T. E. Nogueira, D. R. Dias, and C. R. Leles, "Mandibular complete denture versus single-implant overdenture: a systematic review of patient-reported outcomes," Journal of Oral Rehabilitation, 2017.
[23] J. r. G. A. Pucca, "A política nacional de saúde bucal como demanda social," Ciência é Saúde Coletiva, vol. 11, no. 1, pp. 243-246, 2006.

[24] Z. P. da Silva, M. C. S. de Almeida Ribeiro, R. B. Barata, and M. F. de Almeida, "Socio-demographic profile and utilization patterns of the public healthcare system (SUS), 2003- 2008," Ciencia \& Saúde Coletiva, vol. 16, no. 9, pp. 3807-3816, 2011.

[25] M. da Saúde, S. D. à Saúde, and S. D. em Saúde, "Pesquisa Nacional de Saúde Bucal: Resultados Principais," Cadernos de Saúde Pública, vol. 27, no. 1, pp. 4-5, 2012, http://bvsms.saude .gov.br/bvs/publicacoes/pesquisa_nacional_saude_bucal.pdf. 


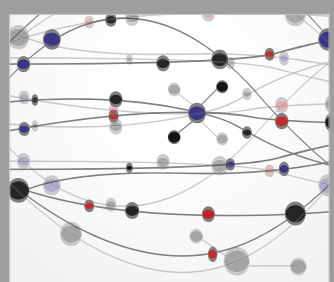

The Scientific World Journal
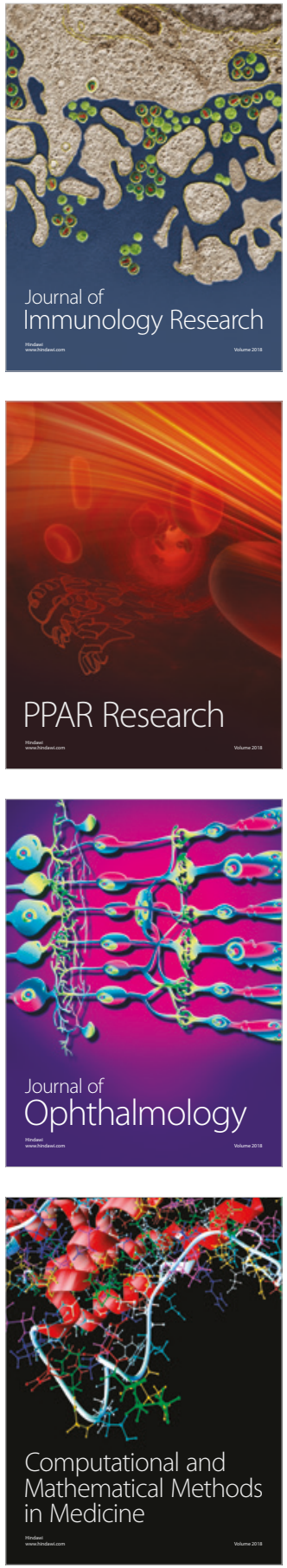

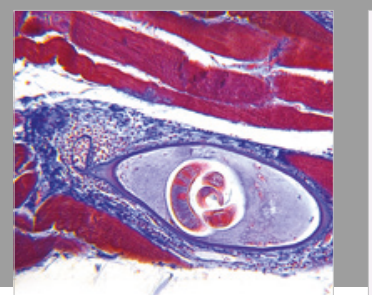

Gastroenterology Research and Practice

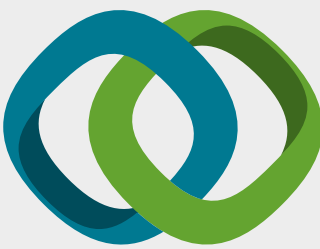

\section{Hindawi}

Submit your manuscripts at

www.hindawi.com
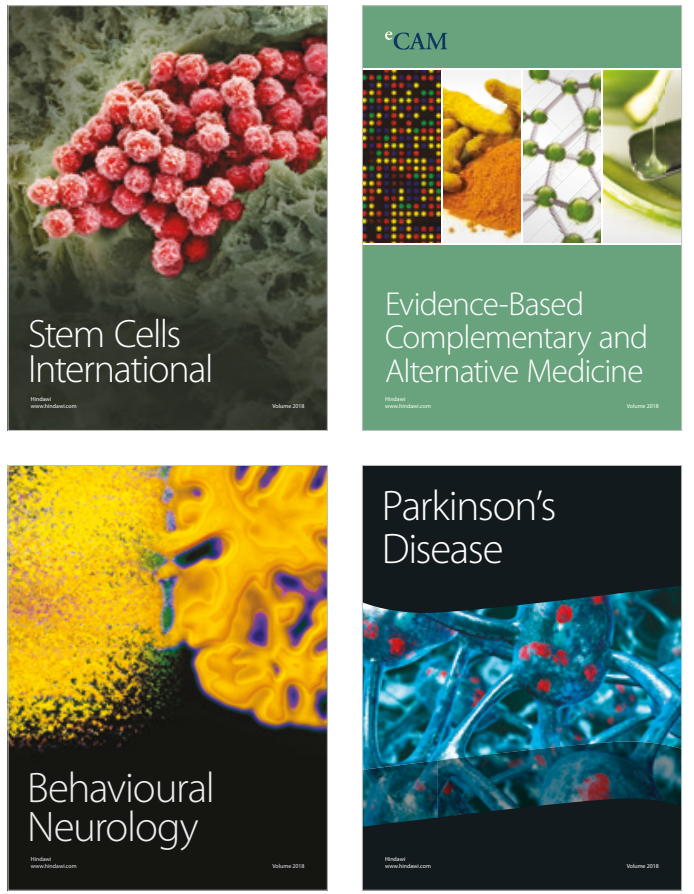

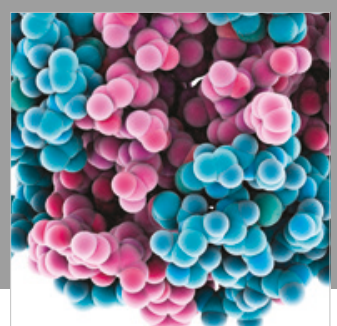

ournal of

Diabetes Research

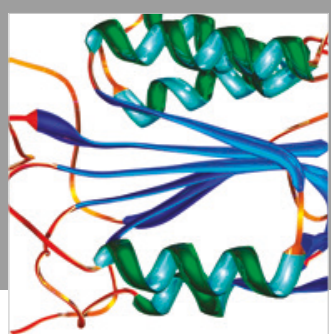

Disease Markers
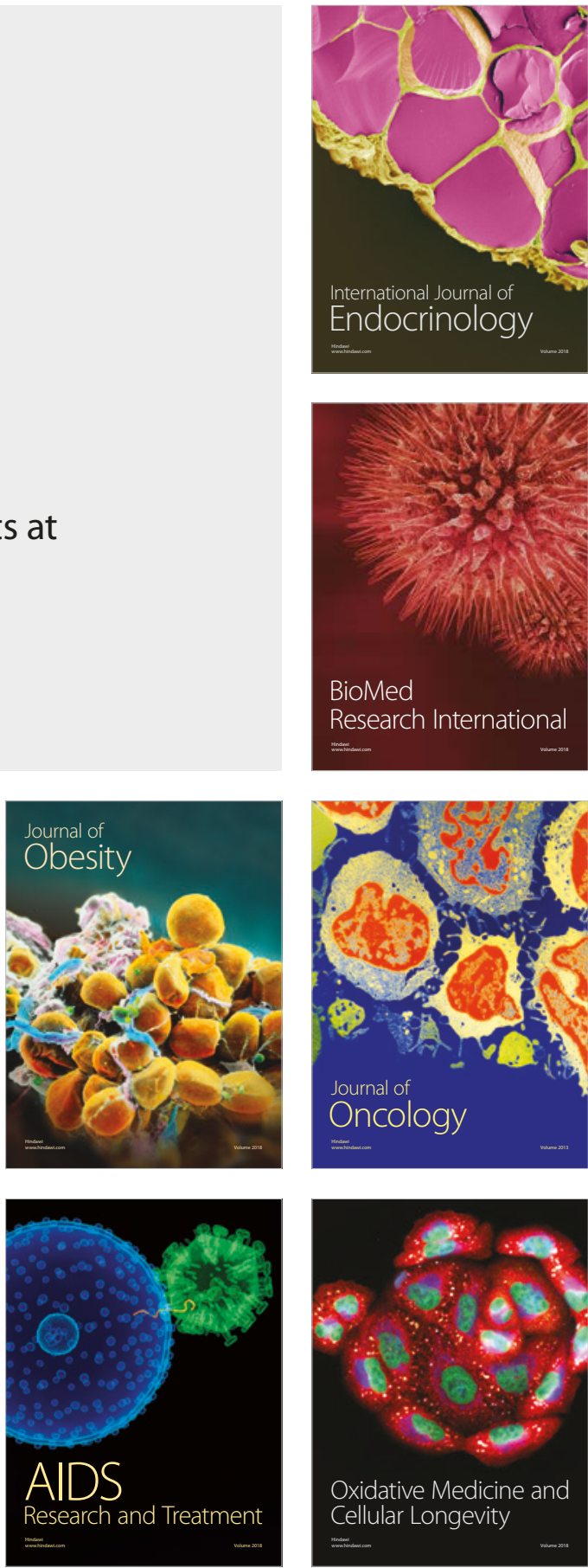